\title{
Research on Start-up Process of No Position Sensor Brushless DC Motor
}

\author{
Shuling Feng ${ }^{1, a}$, Zhilin Ding ${ }^{1, b}$
}

${ }^{1}$ Jiangxi Province, Nanchang Institute of Science \& Technology, Nanchang, Jiangxi, 330103

aemail, bemail,

Keywords: No Position Sensor; Brushless DC Motor; Startup Process

\begin{abstract}
No position sensor Brushless DC motor is widely used in industrial and other fields of automation and consumer areas. Whether it is industrial automation or consumer areas, no position sensor brushless DC motor have achieved more significant results. No position sensor Brushless DC motor has changed the traditional motor load start and other shortcomings, no position sensor Brushless DC motor with high efficiency, small size, cheap and so on, making it an indispensable choice in the field of industrial manufacturing. In this paper, the start-up process of the no position brushless DC motor is put forward, and the method of determining the rotor position detection circuit by the back EMF is put forward. It is hoped that the relevant research will be used for reference and reference.
\end{abstract}

\section{Introduction}

No position sensor Brushless DC motor has the incomparable advantages of traditional motor, no position sensor Brushless DC motor has a long time to use, running fast, cheap, easy maintenance, low production costs, it gradually by the people attention and favor, and gradually be widely applied to a variety of industry areas. No position sensor brushless DC motor start process is more complex, there are often many serious security risks, affected by a variety of factors will cause the motor to start the failure of the results. In this paper, through the study of the start-up process of the no position brushless DC motor, it is very important to reduce the frequency of failure of the motor by combining the traditional method.

\section{No Position Sensor Brushless DC Motor}

No Position Sensor Brushless DC Motor Structure. No position sensor Brushless DC motor is mainly composed of three parts: DC motor body, rotor position detection circuit, power drive circuit. No position sensor Brushless DC motor in the use of the process, in order to ensure the DC motor rotation speed and direction of rotation, DC motor control circuit is also its components. DC motor control circuit in the acceptance of the initial position of the rotor information, through the response of the system for data analysis to determine the DC motor output power switch information, so that the DC motor circuit in the working state [1].

No Position Sensor Brushless DC Motor Working Principle. No position sensor Brushless DC motor works mainly according to the corresponding current law to complete. DC motor is convenient and DC motor can use electronic commutation device, changing the traditional DC motor inverter body larger shortcomings and enhanced DC motor convenience. The electronic commutation ensures the normal operation of the no position sensor brushless DC motor. DC motor in order to maintain a smooth power, should ensure that the opposite electromotive force and DC motor current data consistent. DC motor in the course of the rotor magnetic field will be affected by the magnetic field of the role of the rotor, so that the DC motor counterclockwise rotation. In the process of running the DC motor, the physical quantity of the DC motor must be quantitatively analyzed to ensure the establishment of accurate and practical data information. 


\section{No Position Sensor Brushless DC Motor Start Process Analysis}

Current Build Process. DC motor starts, the DC motor's actual operating speed is zero, the DC motor current speed regulator is generally set to the maximum current. DC motor system in the start-up process requires the maximum current as a support, DC motor regulator shows the maximum control state, DC motor output voltage is relatively high, so the DC motor running speed is reduced. The initial position of the DC motor rotor is often affected by the input current.

Linear Acceleration Process. With the DC motor to start faster, DC motor back electromotive force gradually increased, the DC motor to reduce the net voltage, DC motor current decreases, the current regulator control signal enhancement, DC motor voltage backlash due to interference rate changes Big. With the DC motor back electromotive force increases, the DC motor current can be changed according to system requirements. DC motor in the actual operation process, its running speed reaches the limit state and the DC voltage dynamic tracking ability will be correspondingly increased. Therefore, the start-up time of the DC motor is proportional to the rotation of the DC motor. The starting time of the DC motor is inversely proportional to the starting torque. The greater the rotor starting torque of the DC motor, the smaller the DC motor rotation speed, the DC motor start time the smaller [2].

The Speed Adjustment Process. No position sensor Brushless DC motor start-up speed exceeds the DC motor system saturation state and the DC motor speed regulator will be based on the actual speed of the DC motor to respond. As the DC motor speed gradually increases, the corresponding DC motor speed regulator input difference decreases. DC motor speed regulator response there are two kinds of phenomena: the first, the speed regulator in the DC motor to reach the system speed before the output current is greater than the load current, DC motor speed will appear overshoot. Second, the speed regulator in the DC motor to reach the system speed, the output current is given less than the load current, DC motor speed will not be overshoot.

\section{No Position Sensor Brushless DC Motor Start Process Strategy}

Sensor-less brushless DC motor start-up process control is essential, its core is through the experimental evaluation of the analysis and measurement of position sensor-less brushless DC motor in the start of the relevant physical quantities, by analyzing the rotor position with no position sensor brushless DC the relationship between the motor, the location of the rotor to determine the final use of the correct method of non-position sensor brushless DC motor to start. The rotor initial position detection method and the short-time pulse acceleration method can accurately detect the initial position of the rotor, so that the no position sensor brushless DC motor to change the original operating method to achieve brushless DC motor without reversing start [3].

Rotor Initial Position Detection Method. Rotor initial position detection generally is the no position sensor brushless DC motor power to the motor stator to impose certain amplitude and a fixed voltage pulse value. But the DC motor inductance and its current rise rate is the corresponding. By observing the inductance of the DC motor, the position of the DC motor rotor can be found, and then the initial position of the rotor can be determined according to the current impulse value of the DC motor and the corresponding current response kurtosis value.

In the absence of position sensor brushless DC motor, for example, if the position of the rotor at a, then the DC motor stator, current flux and rotor permanent magnet flux pinch less than 90, then the rotor permanent magnet flux in the DC motor The corresponding flux component and the direction of blocking the current flux are reversed. It can be seen that the DC motor in the power state, its current if the current is less than the current when the coupling current, the DC motor with the same DC pulse, respectively, to the DC motor to form six conductive state. The six conductive states of the DC motor are in the opposite state will hinder the comparison of the response peaks between the currents, resulting in three different comparison results. Two different comparison results can be recorded in binary state, DC The initial position of the rotor of the motor is recorded accordingly, and the initial position of each rotor of the DC motor is marked with the rotor initial 
position detection method.

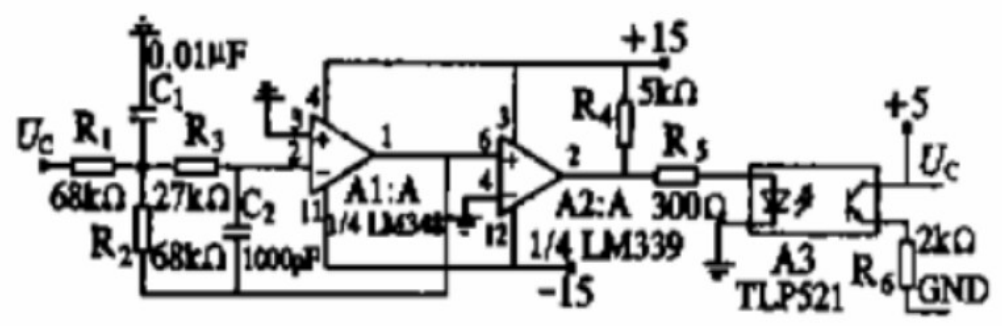

Rotor initial position detection circuit schematic

Short-Time Pulse Acceleration Method. The position of the rotor-less position of the position sensor-less brushless DC motor is completed and the DC motor is started. DC motor six power state, regardless of the initial position of the rotor where can appear three clockwise state and the other three state of the general performance of the counter-clockwise reverse state. In order to extend the DC motor start-up time, should be three clockwise turn on the state of the power to maximize the acceleration. The short-time pulse acceleration method is such that the starting current of the DC motor is large and the initial position of the rotor is often transferred, which may lead to the error of the rotor direction information, which leads to the failure of the DC motor. Therefore, the short-time pulse acceleration method should be used to confirm the exact location of the rotor information, and to ensure that the DC motor into the current size. Short pulse acceleration according to select the appropriate amplitude and pulse width, the rational use of the corresponding response current, to prevent the DC motor start time becomes smaller [4].

\section{Conclusion}

No position sensor brushless DC motor has gradually become the focus of application and research. No position sensor the use of brushless DC motor need to start, no position sensor Brushless DC motor start good or bad affect the work effect. This paper mainly studies the structure and working principle of the no position sensor brushless DC motor from the no position sensor brushless DC motor. The start-up process of the no position brushless DC motor is analyzed, including the current setting process, the linear acceleration process and the speed adjustment process. Combined with the traditional rotor initial position detection method and short-time pulse acceleration method, the final no position brushless DC motor start-up process put forward the corresponding strategy. Through the study and solve many problems in the process of scientific and technological practice, the non-position sensor brushless DC motor is further developed.

\section{References}

[1] Zhou Tong, Huang Jian, Feng Zhitao, etc. DSP-based sensorless brushless DC motor starting control research [J]. Micro-motor, 2013, 46 (3): 42-45, 67.

[2] WU Kai-di, YUAN Deng-ke.Study on Starting Method of Brushless DC Motor without Position Sensor [J]. Electrical and Mechanical Integration, 2014, 20 (11): 33-39.

[3] Zhou Su, Jia Wenjie, Zhong Jilong, etc. Vehicle brushless DC motor starting process strategy and simulation[J]. Journal of Automotive Engineering, 2015, 5 (2): 150-156.

[4] LIU Hong-ping, CUI Ru-fei, GAO Hui-min et al.Study on the Start-up of Position Sensorless Brushless DC Motor [J]. Equipment Manufacturing Technology, 2014, (9): 243-244. 